\title{
THE SOCIAL SURVEY
}

\section{A FIELD FOR CONSTRUCTIVE SERVICE BY DEPARTMENTS OF SOCIOLOGY}

\author{
E. W. BURGESS \\ Ohio State University
}

The social survey of a community is the scientific study of its conditions and needs for the purpose of presenting a constructive program for social advance. The following paper is written for those interested in the development of practical sociology in this country. Its purpose is twofold. It seeks to call attention to the possibilities within the social survey for service by departments of sociology. It attempts in addition to outline a general plan of organization by which the sociologist may best co-operate with the community. The type of relationship described below will be largely based on the experience in social surveys of the department of sociology in the University of Kansas under the leadership of Professor F. W. Blackmar.

To the sociologist there is little novel in the method of the social survey. Perhaps the absence of novelty has prevented an adequate realization of its importance. Indeed a case might well be made for the statement that the social survey was an invention of the sociologist. In every department of sociology in the country beginners in the science have been initiated into this method of community study. The success of the device was immediate and patent. The first-hand study of local conditions vitalized the work of the classroom. Students were convinced that social as well as natural phenomena were susceptible of scientific study. Affective reactions to "conditions as they are" crystallized in the social attitude which Patten terms "the emotional opposition to removable evils."

As an instrument of social measurement the social survey in the hands of the sociologist was until recently confined by the limita- 
tions of the classroom. Its technique was relatively simple. Its examination was more or less superficial. Its results were seldom utilized in social improvement. In short, the social survey in the college was little else than a laboratory toy, like the electric light before Edison, interesting for purposes of exhibition and training, but of slight practical value to the community. Social studies of permanent importance were made, not by departments of sociology, but by individuals, or by groups of social workers. Examples of these are Booth's Life and Labour of the People of London, Rowntree's Poverty, A Study of Town Life, and Jane Addams' HullHouse Maps and Papers.

This statement of the origins of the survey is no reflection on the sociologist. The point may rather be well taken if his contribution has not been made. Is not the work of the social scientist, like that of the natural scientist in the case of the electric light, complete with the discovery of the method? Was not the brilliant Pittsburgh Survey but the work of a social Edison who reduced this discovery of the sociologist to human utilization?

The natural gratification of the sociologist in the transformation of his laboratory method into so efficient an instrument of social investigation should not prevent the perception of the future possibilities of service in connection with the social survey. Indeed, the sociologist has not been indifferent to its recent practical development. In the University of Chicago and Columbia University as well as elsewhere the work in practical sociology has always been correlated with the investigation of city, state, and national problems. Other universities and colleges within the last three or four years have been experimenting with various types of service to the community through the social survey. The interest became so general that two years ago at the Minneapolis meeting of the American Sociological Society a committee was appointed to formulate a plan of organization for social surveys and social investigation. The illness and death of Professor C. R. Henderson, the chairman of the committee, delayed and then checked this movement toward a comparison of the methods and the forms of the social survey and a presentation of a definite plan of organization. 
These two years, however, disclosed a growing appreciation of the value of the social survey. In at least two institutions, the University of Kansas and the University of Southern California, courses in the social survey have been introduced. Of greater significance have been the results of the participation of the sociologist in this method of social study as revealed in the differentiation of distinct forms of the survey. This development has been of two types: (I) surveys of the community by the sociologist upon his own initiative or at the request of the community; (2) surveys of the community in which the sociologist has been called upon to direct and organize the work.

The more common form of service to the community through the social survey by the sociologist has been of the first type. A community, or one or more organizations representing the community, has secured the expert service of the sociologist in making an inventory of its conditions and needs. This study may be general or partial. It may include all aspects of community life, or it may be limited to one or more divisions of the life of the community. The extension division of the University of Iowa is furnishing this type of service to the communities of the state. The department of sociology of the Ohio State University made a significant housing study at Circleville revealing conditions of overcrowding which rival if not surpass those of the worst districts in our largest cities. The social survey of Fargo, North Dakota, was made by a sociologist upon the request of a local organization. This form of the social survey is obviously valuable. The study of conditions by an expert makes possible sure and permanent progress upon the basis of an adequate and impartial examination of the situation. Comparison with conditions in other communities stimulates to social action. Last, but not least, is the present significance and future promise of this tendency of the community to turn to the social scientist for expert service.

This type of survey, however, presents a peril: satisfaction with a level of service which is lower than that which may be achieved. The sociologist should not fall short of the full measure of social opportunity presented. As an expert in social reconstruction he has performed but a part of his service in the analysis and 
the presentation of the needs of the community. His more difficult and more valuable service is his dynamic participation in the social movement of the community. Vital participation may be gauged not so much by the character of his findings as by the nature of his relation to the organic life of the community, that is, to social agencies, social activities, and public opinion. Which type of survey will better educate the public in regard to the social causes of undesirable conditions, will more effectively diffuse the knowledge of scientific methods of prevention and improvement, and will pave the way for united action of all forces in the community to promote a constructive program of social advance? The sociologist should guard against placing himself in the situation where the doing of the service that is insistently demanded may prevent the performance of the larger service which he should be equipped to render.

This larger service, I believe, is to be found in the second type of the survey. The distinctive characteristic of this form of social investigation is the study of local conditions and needs by the community under expert direction. The demand for the survey here as in the other type of the survey comes from the community. But the activity of the community does not cease here. The social expert who is selected to direct the study organizes the community for the work of investigation. This method of organization originated in the Belleville and in the Lawrence social surveys conducted under the direction of the department of sociology of the University of Kansas.

The first principle of this type of survey is that the community as a whole should be organized to promote the survey movement. If feasible, every civic, commercial, religious, and social organization should participate in the demand for the survey. In Belleville, a town of 2,300 persons, the local welfare society, representing practically all the civic interests in the community, initiated and promoted the survey movement. In Lawrence, eight organizations, namely, the Civic Study Club, the Federated Brotherhoods, the Federation of Women's Clubs, the Merchants' Association, the Ministers' Alliance, the Missionary Union, the Parent-Teachers' Association, the Social Service League, united in the request for the 
survey and elected representatives as members of the general social survey committee. This union of social agencies for the purpose of studying conditions is necessary if the survey is to be an organic expression of the social consciousness. A high degree of integration of organized public opinion is thus secured through the general committee representing all the voluntary organizations of the community.

The second principle of this type of the survey is that the study of conditions of life be made by the community under the direction of the expert in the technique of surveys. The sociologist is, or at any rate should be, specially trained to perform this service. $\mathrm{He}$ needs skill in two arts: the technical survey methods, and the technique of directing the organization of the community.

In the Kansas surveys the application of these principles took the following form. The general survey committee, composed of representatives of the organized community life, elected an executive committee to co-operate with the director of the survey, a sociologist, in the organization of the work of investigation. The function of the executive committee was twofold, in regard both to the raising of the finances and to the organization of the investigation. First, a method of raising funds to meet the necessary expenses of the survey was adopted and put in charge of a carefully selected finance committee. Secondly, the executive committee co-operated with the director of the survey in organizing the community. In the Kansas surveys the following divisions of the field were made: ( $\mathrm{r}$ ) topography and population; (2) community planning; (3) municipal administration; (4) trade, industry, and labor; (5) public health; (6) housing; (7) dependency; (8) delinquency; (9) recreation; (ro) education; (II) churches and religion. Committees with a membership varying in size with the nature of the field of study were appointed to co-operate with the director and his staff of field workers.

As valuable as the organizing function of the director of the survey is his service in securing the co-operation of experts in the different special fields of investigation. The sociologist in his direction of the survey is able, not only to utilize the concrete practical knowledge of the local members of the committees of 
investigation, but also to bring to their assistance the special knowledge of experts in the university and in the departments of state. The director of the survey from his point of vantage in the university may offer the community the skilled service of different departments of the university: sociology, economics, political science, history, psychology, education, the extension division, etc. In addition, Kansas experience indicates that he may readily secure the invaluable co-operation of the state departments, such as the state board of health, the department of public instruction, the department of labor and industry. Thus, the social survey, if wisely organized, places at the service of the community both the expert knowledge of the university and the technical resources of the state.

Such, then, in substance is the outline of the organization of community self-study under expert direction. The distinctive advantages of this type of survey deserve further consideration.

The fundamental value of this type of survey lies in its organic relation to the community consciousness. The social survey of the community by the community signifies the development of teamwork. The sociologist as the director is in the position of the coach to the football team. The organization of local committees of investigation signifies a higher integration of the social consciousness. The psychological division of the community into the extremes of "boosters" and of "knockers" disappears before the constructive attitude involved in the scientific study of social problems. The social survey as related to social consciousness may well be described as a method of social introspection checked up by the statistical measurements and the comparative standards of the social expert. Experience shows that the following consequences arise from this type of the organic relation of the sociologist to the community. First, the study of the community by the community under expert direction secures the training of local workers. Secondly, this training of the active social workers of a community often involves on their part a complete change of attitude toward social problems. Concrete, practical experience in the use of scientific methods of investigation tends to rationalize the expression of the humanitarian interest. Thirdly, this participation and 
training of workers in the survey furnish a large and efficient group in the community ready and prepared to promote the program of constructive social advance proposed by the survey. On this last point the results of the Belleville and the Lawrence surveys speak for themselves. In Belleville the president of the local welfare society which conducted the survey was elected mayor upon a platform containing several of the most important recommendations of the survey. In Lawrence before the printing of the report three ordinances were enacted as direct results of the survey: one providing for the inspection and the supervision of the milk supply of the city, another establishing housing standards, and another creating a board and superintendent of public welfare.

A second advantage of this type of the survey is found in the nature of its stimulus to the sociologist and to the department of sociology. The sociologist as director of community self-study has opportunity for expression in the two arts in which he has specialized: first, in the use of the impersonal tools of investigation, of statistics, and of interpretation, and, secondly, in the employment of the personal technique required for organizing co-operation and team-work.

The self-expression of the sociologist through the exercise of the "instinct of workmanship" in both organizing and directing community self-study brings out the possibilities of united action on the part of the several social sciences. A feature of the co-operation involved in this type of the survey fulfils one of the historic claims of the sociologist. The director of the social survey, by securing the co-operation of sociologist, political scientist, economist, historian, and psychologist, demonstrates the functional unity of social science. The problems of the community impinge squarely upon the sociologist, but their satisfactory solution demands the united action of all social scientists. Historically, it is fitting that the sociologist should participate in organizing concerted effort. It is also obvious that this union of activity is more readily secured where the sociologist is the director of community study than where his function is merely to report specific individual findings. The larger work of the sociologist, then, lies in the organization, not 
only of the community, but also of the expert service of the university and of the state.

There is still another advantage of this type of the survey to sociologists and departments of sociology. The stimulus of research vitalizes the work of the classroom. Society is the laboratory of the sociologist. The social survey provides a unique opportunity both for investigation and for social construction, both for the analysis of mental attitudes and for the study of the control of forces in securing improvement. To the advanced student the social survey affords severe and stimulating training in the technique of investigation and in the art of social action.

The third consideration in favor of this type of the survey inheres in the very nature of the participation of the sociologist in the social movement. Herein lies the solution of the problem of democracy and the expert. The method of community self-study under the direction of the specialist involves the co-operation of the group and the expert. The specialist must of necessity demonstrate his skill and his worth in the acid test of the concrete practical problem; the community realizes at first hand the superiority of the new over the old method. Community self-study under expert direction is democracy being at school to the social scientist. The social survey is to the community what the demonstration station is to the farmer.

The solution of the problem of democracy and the expert is, at best, of secondary importance to the function that the social survey may play in social progress. We have all been surprised and chagrined at the apparently slow onward movement of reform. The word "apparently" was used advisedly for the reason that we are prone to gaze on the superficial indications of change and to be unobservant of the deeper currents that shape our social life. Our reform movements of the past have too often been grounded upon the naive idea that all that was needed was a simple substitution of the good "outs" for the bad "ins." Of course, no mere mechanical shift can have permanent value. What is necessary is an organic transformation of habits of sentiment, thought, and action of the American people. This change of heart and head cannot be efficiently effected upon a nation-wide scale; it must take place on 
a community basis. The hamlet, the village, the town, the neighborhood, the city are, from the standpoint of social psychology, the units for the achievement of democratic progress. The family is too small, the state and the nation are too large. In the community the problems of city planning, municipal housekeeping, public health, housing, delinquency, dependency, recreation, education, and social religion are to be worked out. The construction of the American life of the future is fundamentally a problem of the community. The social survey, then, of the type of community self-study under expert direction is the initial step toward the practical realization of efficient and socialized democracy.

A word, in conclusion, should be said in regard to the relation of the sociologist to agencies already in the field. By no implication should this paper be considered an argument for the monopolization of the social survey by departments of sociology. The department of surveys and exhibits of the Russell Sage Foundation has performed fine pioneer service in a series of effective surveys. No doubt, the leadership of the social survey movement will continue with this institution. Yet this one agency cannot hope to respond to all the calls for investigation and so must neglect the smaller cities and towns altogether. The university, on the contrary, with its specialists in all the varied aspects of community life constitutes an unorganized force of experts, a potential staff of social surveyors. The communities, too, are becoming more and more acutely aware of their social problems and are turning to departments of sociology for assistance in their solution. The task of the sociologist is twofold: to secure the co-operation of specialists in the university and of the departments of state and to organize the community for self-investigation under expert direction. For this reason the social survey is an inviting field for constructive service by departments of sociology. 